\title{
The Relationship between Coronary Atherosclerosis and Dental Pulp Calcification
}

ISSN: 2637-7764

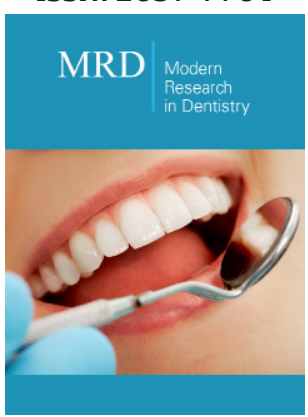

*Corresponding author: Helen Rushdi Ayoubi, Department of Endodontics and Operative Dentistry, Faculty of Dentistry, Damascus University, Fayez Mansour Street, P.O. BOX: 30621, Mazzeh Highway, Damascus, Syria

\section{Submission: 些 August 06, 2021}

Published: 制 September 02, 2021

Volume 6 - Issue 5

How to cite this article: Helen Rushdi Ayoubi. The Relationship between Coronary Atherosclerosis and Dental Pulp Calcification. Mod Res Dent. 6(5). MRD. 000646. 2021. DOI: 10.31031/MRD.2021.06.000646

Copyright@ Helen Rushdi Ayoubi, This article is distributed under the terms of the Creative Commons Attribution 4.0 International License, which permits unrestricted use and redistribution provided that the original author and source are credited.

\section{Helen Rushdi Ayoubi*}

Assistant Professor, Department of Endodontics and Operative Dentistry, Faculty of Dentistry, Damascus University, Damascus, Syria

\begin{abstract}
A coronary artery disease is considered an important cause of mortality in society and imposed the extensive costs for patients. Therefore, the aim of this mini review was to evaluate the relationship between coronary arteriosclerosis and dental pulp calcification in patients. Dental radiography has the potential to be used as a rapid screening method for the early detection of coronary artery disease. Given the routine request for panoramic radiographs in dental examinations, dentists can use the technique to screen individuals with a risk of Cardiovascular Diseases (CVD). This shows the role of dentists in the general health of the public in society.
\end{abstract}

Keywords: Calcification; Pulp Stone; Coronary Artery Disease; Panoramic Radiography

\section{Introduction}

Mineral deposits can be formed in ectopic areas or dystrophic lesions under various conditions in the body [1], this mineral deposition can make changes with the appearance of a lesion or plaque and be observed radiographically [1].

Calcification of atherosclerotic lesions is very common [1], the mechanism of atherosclerotic calcification can be performed as passive mineral deposition, bone formation, or remodeling [1]. Atherosclerosis can occur as a chronic disease and increases by aging, where during the process, the cholesterol crystal deposits attach to the inner layers of the arteries [2] and gradually increase in size and volume, followed by calcium deposition.

The main characteristic of atherosclerosis is narrowing and loss of elasticity of blood vessels [2]. On the other hand, the most common cause of myocardial ischemia is the presence of atherosclerotic lesions in one or more coronary arteries [3]. This process reduces myocardial blood flow and cause insufficient myocardial perfusion by the coronary artery [3] and identified as one of the main causes of mortality in the world [4].

Pulp stones are calcified bodies in the dental pulp of the teeth [5], classified into two classes of "true" and "false" [5]. True pulp stones are quite rare and contain dentine with specific dentinal tubules surrounded by odontoblast cells [5], whereas the false pulp stones are made up of concentric layers of mineralized tissue created through the mineralization of calcium on vascular epithelial and neuron cells [6]. In fact, the collagen bundles of vascular and neural sheaths are the center of calcification [6]. Pulp stones are more reported in the coronal pulp, compared to the apical pulp [7], and the pulp stones larger than $200 \mu \mathrm{m}$ can be detected in radiographic assessments [7].

However, the main cause of pulp stones remains unknown [8], several factors have been recognized for their formation including aging [9] and idiopathic factors [10]. Other factors involved in this area include dental orthodontic movements [11], prolonged exposure to stimuli such as decay and deep fillings [12], surgical procedures and periodontal diseases [13]. This condition also occurs in patients with systematic diseases [14], genetic diseases 
(e.g., Dentin Dysplasia and Dentinogenesis Imperfecta) [15], and syndromes such as Van der Wounde [16] and Marfan syndrome [17]. Furthermore, evidence shows that hypercalcemia, gout and kidney stones $[18,19]$ could be predisposing factors for pulp calcification.

Since pulp stones are ectopic calcification on vascular walls, they may have similar pathogenesis to the calcifications of other body organs, including coronary artery atherosclerosis. Therefore, detecting them in normal dental radiographs can be used as a screening method for early detection of cardiovascular diseases. Taking panoramic dental radiograph is a part of a dental checkup, and pulp stones can be detected in panoramic radiographs as much as they can be identified in periapical and bitewing radiographs [20].

Most studies reported that the frequencies of pulp stones were highest in molars [12,20-24]. Given the fact that pulp stones smaller than $200 \mu \mathrm{m}$ are not shown in radiographs, it is possible that the prevalence of pulp stones is estimated lower than the real amount [7]. Otherwise, the use of Cone Beam Computed Tomography (CBCT) imaging for all teeth is not ethical due to the high $\mathrm{x}$-ray dose. Therefore, normal radiographs are recognized as a non-invasive method in clinical assessments.

In some studies, the pulp of extracted teeth is assessed in terms of histopathology to evaluate the prevalence of pulp stones [25]. In these studies, it is also possible to estimate less than the actual value if adequate sections of the tooth have not been prepared [25].

In fact, there is debate and uncertainty about the correlation between pulp stones and systematic disorders. In the one of studies, Sener et al. [26] found that there was no association between cardiovascular diseases and pulp stones. Also, in a histological assessment, Krell et al. [27] reported that there were no atherosclerotic changes in dental pulp vessels of atherosclerotic monkeys. Alsweed et al. [1], Horsley et al. [28], and Yilmaz et al. [29] investigated the dental pulp calcification and calcification in the carotid artery bifurcation area on panoramic radiography, and they found no significant statistical relationship in this regard.

It is notable that the calcification of carotid arteries was evaluated in these studies and not coronary arteries, while the nature of vascular calcification was considered in both states. So, the different results are obtained. One of the causes of this difference is the use of panoramic radiographs to assess carotid calcification.

Furthermore, angiography images are used in the assessment of coronary arteries, which yield more accurate results. Besides, some studies have shown a strong correlation between dental pulp stones and systematic diseases, where Mathew etal. [30] were found that there was a significant correlation between the prevalence of dental pulp stones and systematic diseases, especially Diabetes Mellitus (DM) and Cardiovascular Diseases (CVD). According to the results of these researchers, $86 \%$ of the cases had pulp stones with DM or CVD. It was also reported that the prevalence of pulp stones was higher in male subjects and the elderly. Similarly, Sridevi et al. [31] found that the patients who suffer from coronary artery disease $(100 \%)$ had a high chance of developing pulp stones, but in this study, no significant difference was observed in terms of prevalence based on gender. In addition, Edds et al. [32] reported after using the pericardial radiography that individuals with pulp stones were (4.4) times more prone to CVD, compared to those without pulp stones. Likewise, results presented by Panwar et al. [33] were indicative of a high chance of pulp stones in patients with CAD. Also, the high presence of pulp stones in different teeth makes individuals prone to CVD, especially in the presence of other risk factors.

Given the routine request for panoramic radiographs in dental examinations, dentists can use the technique to screen individuals with a risk of CVD. This shows the role of dentists in the general health of the public in society.

\section{References}

1. Alsweed A, Farah R, Satheeshkumar PS, Farah R (2019) The prevalence and correlation of carotid artery calcifications and dental pulp stones in a Saudi Arabian population. Diseases 7(3): 50.

2. Madden R, Hodges J, Salmen C, Rindal D, Tunio J, et al. (2007) Utility of panoramic radiographs in detecting cervical calcified carotid atheroma. Oral Surg Oral Med Oral Pathol Oral Radiol Endod 103(4): 543-548.

3. Jinnouchi H, Kolodgie FD, Romero M, Virmani R, Finn AV (2020) Pathophysiology of coronary artery disease. In: Vessel Based Imaging Techniques, Springer, Berlin, Germany, pp: 211-27.

4. Monteiro IA, Ibrahim C, Albuquerque R, Donaldson N, Salazar F, et al. (2018) Assessment of carotid calcifications on digital panoramic radiographs: Retrospective analysis and review of the literature. J Stomatol Oral Maxillofac Surg 119(2): 102-106.

5. Memon M, Kalhoro FA, Shams S, Arain S (2018) Pulp stone. The Professional Medical Journal 25(7): 992-996.

6. Siddiqui SH, Mohamed AN (2016) Calcific metamorphosis: A review. Int J Health Sci (Qassim) 10(3): 437-442.

7. Ertas ET, Inci M, Demirtas A, Ertas H, Yengil E, et al. (2014) A radiographic correlation between renal and pulp stones. West Indian Med J 63(6): 620-625.

8. Kiseleva D, Shagalov ES, Zaitceva MV, Pankrushina EA, Sustavov SG, et al. (2020) Physical and chemical characteristics of pathogenic tooth pulp calcifications. In: Minerals, Structure, Properties, Methods of Investigation, Springer, Berlin, Germany, pp: 89-94.

9. Goldberg M (2014) Pulp aging: fibrosis and calcospherites. In: The Dental Pulp, Springer, Berlin, Heidelberg, Germany, pp: 113-21.

10. Nagaraj T, Sinha P, Goswami RD, Veerabasaviah BT (2014) A radiographic assessment of the prevalence of idiopathic pulp calcifications in permanent teeth: a retrospective radiographic study. Journal of Indian Academy of Oral Medicine \& Radiology 26(3): 248-252.

11. Ertas ET, Veli I, Akin M, Ertas H, Atici MY (2017) Dental pulp stone formation during orthodontic treatment: A retrospective clinical follow up study. Niger J Clin Pract 20(1): 37-42.

12. Sisman Y, Aktan AM, Tarım Ertas E, Çiftçi ME, Şekerci AE (2012) The prevalence of pulp stones in a Turkish population. A radiographic survey. Med Oral Patol Oral Cir Bucal 17(2): e212-e217.

13. Haerian Ardakani A, Maleki L, Abbasi Salimkandi S (2017) Evaluation and comparison of frequency of pulp stones in histologic sections of 
severe chronic periodontitis affected teeth and healthy teeth. Journal of Shahid Sadoughi University of Medical Sciences and Health Services 24(10): 790-797.

14. Nayak M, Kumar J, Prasad LK (2010) A radiographic correlation between systemic disorders and pulp stones. Indian J Dent Res 21(3): 369-373.

15. Carroll MK, Duncan WK, Perkins TM (1991) Dentin dysplasia: review of the literature and a proposed subclassification based on radiographic findings. Oral Surg Oral Med Oral Pathol Oral Radiol Endod 72(1): 119125.

16. Kantaputra PN, Sumitsawan Y, Schutte BC, Tochareontanaphol C (2002) Van der Woude syndrome with sensorineural hearing loss, large craniofacial sinuses, dental pulp stones, and minor limb anomalies: Report of a four-generation Thai family. Am J Med Genet 108(4): 275280.

17. Bauss O, Neter D, Rahman A (2008) Prevalence of pulp calcifications in patients with Marfan syndrome. Oral Surg Oral Med Oral Pathol Oral Radiol Endod 106(6): e56-61.

18. Gabardo MC, Wambier LM, Rocha JS, Küchler EC, de Lara RM, et al (2019) Association between pulp stones and kidney stones: a systematic review and meta-analysis. J Endod 45(9): 1099-1105.

19. Movahhedian N, Haghnegahdar A, Owji F (2018) How the prevalence of pulp stone in a population predicts the risk for kidney stone. Iran Endod J 13(2): 246-250.

20. Yousuf MA, Antony S (2018) Radiographic assessment of prevalence of pulp stones in South Indian population. Drug Invention Today 10(3): 3162-3165.

21. Hsieh CY, Wu YC, Su CC, Chung MP, Huang RY, et al. (2018) The prevalence and distribution of radiopaque, calcified pulp stones: a cone-beam computed tomography study in a northern Taiwanese population. J Dent Sci 13(2): 138-144.

22. Kalaji MN, Habib AA, Alwessabi M (2017) Radiographic assessment of the prevalence of pulp stones in a Yemeni population sample. Eur Endod J 2(1): 1-6.

23. Ranjitkar S, Taylor JA, Townsend GC (2002) A radiographic assessment of the prevalence of pulp stones in Australians. Aust Dent J 47(1): 36-40.
24. Hamasha AA, Darwazeh A (1998) Prevalence of pulp stones in Jordanian adults. Oral Surg Oral Med Oral Pathol Oral Radiol Endod 86(6): 730732 .

25. Aleksova P, Serafimoski V, Popovska M, Ristovski M (2013) Pulp stones can help in detection of calculus in the kidneys and/or in the bile-fact or fiction? Pril (Makedon Akad Nauk Umet Odd Med Nauki) 34(2): 159167.

26. Şener S, Cobankara FK, Akgünlü F (2009) Calcifications of the pulp chamber: prevalence and implicated factors. Clin Oral Investig 13(2): 209-215.

27. Krell KV, McMurtrey LG, Walton RE (1994) Vasculature of the dental pulp of atherosclerotic monkeys: light and electron microscopic findings. J Endod 20(10): 469-473.

28. Horsley SH, Beckstrom B, Clark SJ, Scheetz JP, Khan Z, et al. (2009) Prevalence of carotid and pulp calcifications: a correlation using digital panoramic radiographs. Int J Comput Assist Radiol Surg 4(2): 169-173.

29. Yilmaz SG, Yilmaz F, Bayrakdar IS, Harorli A (2019) The Relationship between carotid artery calcification and pulp stone among hemodialysis patients: A retrospective study. Saudi J Kidney Dis Transpl 30(4): 755763.

30. Mathew ST, Al Mutlaq MA, Al Eidan RF, Al Khuraisi DM, Adam H (2019) Prevalence of pulp stones and its relation with cardiovascular diseases and diabetes mellitus using digital radiographs: a retrospective study. Ann Dent Spec 7(4): 18.

31. Sridevi K, Thejasri V, Malathi S, Ch E, Reddy S, et al. (2019) Pulp stones as risk predictors for coronary artery disease (CAD). Ann Med Health Sci Res 9: 509-513.

32. Edds AC, Walden JE, Scheetz JP, Goldsmith LJ, Drisko CL, et al. (2005) Pilot study of correlation of pulp stones with cardiovascular disease. J Endod 31(7): 504-506.

33. Panwar PS, Debkant J, Chowdary NG, Dwijendra KS, Kumar P, et al. (2019) Pulp stones as risk predictors for coronary artery disease: An intriguing, prevalence study. Research in Cardiovascular Medicine 8(2): 54. 